\title{
Frequency distribution of helminths of wolves in Kazakhstan
}

\author{
Abdybekova, A M ; Torgerson, P R
}

\begin{abstract}
Between 2001 and 2008 a total of 41 wolves (Canis lupus) were necropsied in southern Kazakhstan and their intestinal parasite fauna evaluated. Of these animals $8(19.5 \%)$ were infected with Echinococcus granulosus, 15 (36\%) with Taenia spp, 13 (31.7\%) with Dypilidium caninum, 5 (12.2\%) with Mesocestoides lineatus, 15 (36.6\%) with Toxocara canis, 16 (39\%) with Toxascaris leonina, 8 (19.5\%) with Trichuris vulpis, 9 (22\%) with Macracanthorhynchus catulinus and 1 (2.4\%) with Moniliformis moniliformis. All parasites had an aggregated distribution which followed a zero inflated or hurdle model. Although a small convenience sample of wolves, the results indicate a high prevalence of infection with E. granulosus. The mean abundance (1275 E. granulosus per wolf) was high with individual infected wolves carrying intensities of several thousand parasites. As wolves are common in Kazakhstan they may act as an important host in the transmission of this zoonotic parasite. The wolves were sampled from an area of Kazakhstan where there is a high prevalence of hydatid cysts in livestock and where echinococcosis has been observed in wild ungulates.
\end{abstract}

DOI: https://doi.org/10.1016/j.vetpar.2011.09.004

Posted at the Zurich Open Repository and Archive, University of Zurich

ZORA URL: https://doi.org/10.5167/uzh-57893

Journal Article

Accepted Version

Originally published at:

Abdybekova, A M; Torgerson, P R (2012). Frequency distribution of helminths of wolves in Kazakhstan. Veterinary Parasitology, 184(2-4):348-351.

DOI: https://doi.org/10.1016/j.vetpar.2011.09.004 


\section{Frequency Distributions of helminths of wolves in Kazakhstan.}

5 A. M. Abdybekova ${ }^{1} \&$ P. R. Torgerson ${ }^{2}$

7 Abstract

8 Between 2001 and 2008 a total of 41 wolves (Canis lupus) were necropsied in southern Kazakhstan

9 and their intestinal parasite fauna evaluated. Of these animals 8 were infected with Echinococcus 10 granulosus (19.5\%), 15 (36\%) with Taenia spp, 13 (31.7\%) with Dypilidium caninum, 5 (12.2\%) 11 with Mesocestoides lineatus, 15 (36.6\%) with Toxocara canis, 16 (39\%) with Toxascaris leonina, 8 12 (19.5\%) with Trichuris vulpis, 9 (22\%) with Macracanthorhynchus catulinus and 1 (2.4\%) with 13 Moniliformis moniliformis (2.4\%). All parasites had an aggregated distribution which followed a 14 zero inflated or hurdle model. Although a small convenience sample of wolves, the results indicate 15 a high prevalence of infection with E. granulosus. The mean abundance (1275 E. granulosus per 16 wolf) was high with individual infected wolves carrying intensities of several thousand parasites. 17 As wolves are common in Kazakhstan they may act as an important host in the transmission of this 18 zoonotic parasite.

$22{ }^{1}$ Kazakh State Veterinary Research Institute, Almaty, Kazakhstan

$23{ }^{2}$ Section of Epidemiology, Vetsuisse Faculty, University of Zurich, Switzerland

24 email: paul.torgerson@access.uzh.ch

27 Key words: Echinococcus, wolves, helminths, epidemiology, zero-inflated, Kazakhstan 
28 Since independence from the Soviet Union echinococcosis has been an emerging disease in 29 Kazakhstan (Torgerson et al., 2002; 2006). This has been characterised by a dramatic increase in the 30 numbers of human surgical cases recorded. The prevalence of echinococcosis in livestock in 31 Kazakhstan is high (Torgerson et al., 2003a) and there is also a high prevalence in the rural dog 32 population. Prevalences in shepherd dog populations have been recorded at over 20\% (Torgerson et 33 al., 2003b). Little is known concerning the role of wild carnivores in the transmission of 34 Echinococcus granulosus in Kazakhstan. However wolves (Canis lupus) are known to be important 35 definitive hosts in the northern hemisphere (Craig and Craig, 2005).

Control and elimination of echinococcosis is possible and has been achieved in several areas such as New Zealand, Tasmania and Cyprus (Craig and Larrieu, 2006). Successful elimination programmes have usually been achieved when the parasite is maintained by a domestic cycle (such as dogs and sheep) and the distribution is limited geographically, such as on an island, making control of reintroduction feasible. Kazakhstan is a large country bordered by other endemic countries. In addition it has one of the world's largest wolf populations which is estimated at between 35,000 and 45,000 individuals (Lobachev and Bekenov, 2003). This provides the opportunity for E. granulosus to be maintained in a large susceptible wild life reservoir which could hamper efforts at control of this parasite. Furthermore, little is known with regard to the parasite fauna of wolves and factors such as frequency distribution of parasites that may affect transmission.

Because of their high populations, wolves are considered a threat to livestock in many areas of Kazakhstan and there are government incentives to control wolf populations. This study describes the helminthological findings from 41 wolves, shot by hunters in southern Kazakhstan between 2001 and 2008. The wolves were from South Kazakhstan, Taras and Almaty Oblasts and shot during the winter months. The gastrointestinal tracts of wolf carcasses supplied by hunters were removed for further examination.

Helminths were recovered from the gastrointestinal tract by the method of Skryabin and Petrov (1964). The small intestine was opened along the entire length, the mucosa scraped and the contents flushed with water. The flushing volume was adjusted with water to 2 liters and thoroughly mixed. This was examined in aliquots of $50 \mathrm{ml}$ in Petri dishes using binocular microscope. Cestode species were mounted and stained with carmine, and nematodes cleared in lactic acid with glycerol. Helminth species were morphologically identified according to Abuladze et al. (1990) and Skryabin and Petrov (1964).

The data were entered onto an excel spreadsheet and imported into R (www.r-project.org).

60 Summary prevalence for each parasite was calculated and the 95\% exact binomial confidence

61 intervals. For analysis of abundance, the best fitting frequency distribution was used a number of 
general linear models (GLM) or zero-inflated generalised Poisson models (ZIGP) were used. The optimal frequency distribution for each helminth species was determined as described previously (Ruegg et al., 2008; Ziadinov et al., 2010). The 95\% confidence intervals of the mean parasite abundance were calculated from the likelihood profile.

The prevalence, abundance and optimal frequency distributions of each parasite species is given in table 1 .

Table 1. Prevalence, abundance and frequency distributions of parasites of wolves in Kazakhstan

\begin{tabular}{|c|c|c|c|c|}
\hline Parasite & $\begin{array}{l}\text { Prevalence } \\
(\%) \\
(95 \% \mathrm{CIs})\end{array}$ & $\begin{array}{l}\text { Mean Abundance } \\
(95 \% \text { CIs })\end{array}$ & $\begin{array}{l}\text { Frequency }^{1} \\
\text { distribution }\end{array}$ & Parameters $^{2}$ \\
\hline E. granulosus & $\begin{array}{l}19.5 \\
(8.8-34.9)\end{array}$ & $\begin{array}{l}1275 \\
(405-2342)\end{array}$ & $\begin{array}{l}\text { Zero-inflated } \\
\text { negative } \\
\text { binomial }\end{array}$ & $\begin{array}{l}0.80 \text { (zero) } \\
6532 \text { (mean) } \\
2.56 \text { (theta) }\end{array}$ \\
\hline Taenia spp & $\begin{array}{l}36.6 \\
(22.1-53.1)\end{array}$ & $\begin{array}{l}1.15 \\
(0.63-1.76)\end{array}$ & $\begin{array}{l}\text { Zero-inflated } \\
\text { Poisson }\end{array}$ & $\begin{array}{l}0.614 \text { (zero) } \\
2.97 \text { (mean) }\end{array}$ \\
\hline Dipylidium caninum & $\begin{array}{l}31.7 \\
(18.1-48.1)\end{array}$ & $\begin{array}{l}3.39 \\
(1.66-5.46)\end{array}$ & $\begin{array}{l}\text { Zero-inflated } \\
\text { negative } \\
\text { binomial }\end{array}$ & $\begin{array}{l}0.675 \text { (zero) } \\
8.61 \text { (mean) } \\
2.46 \text { (theta) }\end{array}$ \\
\hline Mesocestoides lineatus & $\begin{array}{l}12.2 \\
(4.1-26.2)\end{array}$ & $\begin{array}{l}0.82 \\
(0.194-1.804)\end{array}$ & $\begin{array}{l}\text { Zero-inflated } \\
\text { Poisson }\end{array}$ & $\begin{array}{l}0.878 \text { (zero) } \\
6.99 \text { (mean) }\end{array}$ \\
\hline Toxocara canis & $\begin{array}{l}36.6 \\
(22.1-53.1)\end{array}$ & $\begin{array}{l}5.52 \\
(2.51-9.81)\end{array}$ & $\begin{array}{l}\text { Zero-inflated } \\
\text { negative } \\
\text { binomial }\end{array}$ & $\begin{array}{l}0.623 \text { (zero) } \\
15 \text { (mean) } \\
1.65 \text { (theta) }\end{array}$ \\
\hline Toxascaris leonina & $\begin{array}{l}39 \\
(24.2-55.5)\end{array}$ & $\begin{array}{l}4.9 \\
(2.39-8.20)\end{array}$ & $\begin{array}{l}\text { Zero-inflated } \\
\text { negative } \\
\text { binomial }\end{array}$ & $\begin{array}{l}0.603 \text { (zero) } \\
12.54(\text { mean }) \\
2.15(\text { theta })\end{array}$ \\
\hline Trichuris vulpis & $\begin{array}{l}19.5 \\
(8.8-34.9)\end{array}$ & $\begin{array}{l}1.12 \\
(0.46-1.95)\end{array}$ & $\begin{array}{l}\text { Zero-inflated } \\
\text { Poisson }\end{array}$ & $\begin{array}{l}0.80 \text { (zero) } \\
5.86(\text { mean })\end{array}$ \\
\hline $\begin{array}{l}\text { Macracanthorhynchus } \\
\text { catulinus }\end{array}$ & $\begin{array}{l}22 \\
(10.6-37.6)\end{array}$ & $\begin{array}{l}1.32 \\
(0.634-2.00)\end{array}$ & $\begin{array}{l}\text { Zero-inflated } \\
\text { Poisson }\end{array}$ & $\begin{array}{l}0.78 \text { (zero) } \\
6.10 \text { (mean) }\end{array}$ \\
\hline $\begin{array}{l}\text { Moniliformis } \\
\text { moniliformis }\end{array}$ & $\begin{array}{l}2.4 \\
(0.06-12.9)\end{array}$ & 0.19 & & $\mathrm{NA}^{3}$ \\
\hline
\end{tabular}

${ }^{1}$ Zero inflated and hurdle models were mathematically indistinguishable with this data.

${ }^{2}$ The parameters are proportion zero inflated (zero), mean of positive counts (mean) and constant of aggregation (theta for negative binomial only)

$73{ }^{3}$ Only one animal was infected with this parasite, so no meaningful analysis could be undertaken

The best fit model in each case was the hurdle and zero inflated model. E. granulosus,

77 Dipylidium caninum, Toxocaca canis and Toxascaris lenonina had a zero inflated /hurdle negative 
binomial model with other parasites having a better fit to the zero-inflated/hurdle Poisson model. Hurdle and zero-inflated models were indistinguishable mathematically.

This manuscript reports the frequency distribution and prevalence of a number of parasites of wolves in Kazakhstan. A few caveats must be taken when interpreting the data. The data was collected over a number of years and from a large geographical area in southern Kazakhstan. Thus it can not be seen as a random sample, but a convenience sample from materials provided by hunters. However, with such a top level wild predator it would not be appropriate to take a large random sample for specifically a parasitological investigation, even though the numbers of wolves are relatively high in Kazakhstan. Therefore the only realistic method of obtaining such data is from the methodology described.

Despite this caveat there are a number of important observations in this study. E. granulosus is a common parasite of wolves with 8 of the $41(19.5 \%)$ wolves infected. The abundance of infection was high with an average of 1275 parasites per wolf, or an intensity of 6533 parasites per infected wolf. The prevalence of infection is comparable to that seen in shepherd dogs sampled in the same geographical region. Shepherd dogs had a prevalence of $23 \%$ with an abundance of infection of 631 parasites per dog (Torgerson et al., 2003b). However, the earlier study in dogs may underestimate both the prevalence and abundance of infection as this was estimated by arecoline purgation which has poor diagnostic sensitivity (Ziadinov et al., 2008). Thus it appears that wolves are an important host of this zoonotic parasite in Kazakhstan. The source of infection for these wolves is presently unknown, but future genetic analysis of parasite specimens isolated from wolves, livestock and dogs in southern Kazakhstan may give important clues. Livestock in southern Kazakhstan have a high prevalence of cystic echinococcosis (Torgerson et al., 2003a) and thus could provide a source of infection for wolves. Hydatid cysts have also been recorded in wild ungulates in Kazakhstan. These include the saiga antelope, the Siberian roe deer and wild boar (Baytursinov, 2008, 2009). The source of infection for wolves is an important open question. A self sustaining cycle confined entirely to wild life hosts might hamper efforts at control of this parasite especially if the genotypes involved are the same ones that infected domestic livestock and domestic dogs.

The abundance and prevalence recorded in the present sample of wolves was lower than that recorded in the USA (Foreyt et al., 2009) where approximately $63 \%$ of timber wolves were infected but higher than the 2.9\% recorded in Lithuania (Bagrade et al., 2009). The genotypes infecting wolves in Kazakhstan is presently unknown, but in Spain four of 27 Iberian wolves were infected with the G1 strain of Echinococcus indicating that wolves may help to maintain the sheep - dog life cycle (Sobrino et al., 2006). Likewise in Bulgaria, wolves were infected with the G1 strain (Breyer 
112 et al., 2004). In the Baltic region the G10 strain may infect wolves (Moks et al., 2006) which is 113 likely to be from wild ungulates.

114 The frequency distributions of all the parasite species were highly over dispersed. Each 115 parasite had a best fit to a zero inflated or hurdle model. Zero-inflated and hurdle models have been 116 infrequently used in epidemiological studies of animal parasites. However, the computing software 117 to enable this is now available and important ecological information can be gained from such 118 analysis. Previous examples of the use of such models include Denwood et al. (2008) and Ziadinov 119 et al. (2010). In a zero inflation model there could be true or false zeros (Martin et al., 2005). The 120 true zeros in the present data set may be when the parasite is absent from the host. False zeros might 121 arise where the parasite is present but not detected. The sensitivity of necropsy used in the present 122 study is high thus the latter possibility is improbable. For each parasite examined, the model fit was 123 better for a zero inflated or hurdle model than a standard Poisson or negative binomial GLM. A 124 hurdle model assumes that all zeros are true zeros and the non zero count data is modeled as a 125 truncated count distribution. In our data set, the two models are indistinguishable both in terms of 126 parameters and in terms of likelihood. This is because the probability of a zero count given the 127 mean is very low for each parasite in the non-zero inflated proportion of individuals. Our data 128 therefore indicates for each parasite species an animal has been exposed to a variable number of 129 infectious stages and become infected or alternatively has not been exposed. E. granulosus 130 metacestodes can contain very large numbers of protoscolices each one capable of developing into 131 an adult tapeworm. Thus a single exposure could result in a large but highly variable number of 132 parasites which can be described by the non zero terms of the relevant negative binomial 133 distribution. With some other parasites such as Taenia spp, the infectious insult will be much 134 smaller as with most Taenia species a single metacestode has the potential to develop into a single 135 tapeworm. Thus the infected wolves might be more likely to have a distribution consistent with the non zero terms of the Poisson distribution with Taenia spp...

In conclusion this study demonstrates that wolves in Kazakhstan have a high prevalence and abundance of infection with E. granulosus. It is presently unknown if these wolves are maintaining an entirely wild life cycle becoming infected from prey species or if is spilling over from the domestic cycle through predation of domestic ruminants or scavenging carcasses.

\section{References}

143 Abuladze, K., Demidov, N., Nepoklonov, A. A., Nikol'skii, S., Pavlova, N. V., Stepanov, A. V., 144 1990, Parasitology and parasitic diseases of farm animals. Agropromizdat, 464 p. (in Russian)

Bagrade, G., Kirjusina, M., Vismanis, K., Ozolins, J., 2009, Helminth parasites of the wolf Canis lupus from Latvia. Journal of Helminthology 83, 63-68. 
Baytursinov, K.K., 2008, Current status of helminth fauna of wild ungulates in Kazakhstan. Uzbek Biological Journal 2, 48-54. (in Russian)

Baytursinov, K.K., 2009. Helminths of wild ungulates in Kazakhstan and the dynamics of present day epizootiologically important helminths. Almaty. (in Russian)

Breyer, I., Georgieva, D., Kurdova, R., Gottstein, B., 2004, Echinococcus granulosus strain typing in Bulgaria: the G1 genotype is predominant in intermediate and definitive wild hosts. Parasitology Research 93, 127-130.

Craig, H.L., Craig, P.S., 2005, Helminth parasites of wolves (Canis lupus): a species list and an analysis of published prevalence studies in Nearctic and Palaearctic populations. Journal of Helminthology 79, 95-103.

Craig, P.S., Larrieu, E., 2006, Control of cystic echinococcosis/hydatidosis: 1863-2002. Advances in Parasitology 61, 443-508.

Denwood, M.J., Stear, M.J., Matthews, L., Reid, S.W.J., Toft, N., Innocent, G.T., 2008, The distribution of the pathogenic nematode Nematodirus battus in lambs is zero-inflated. Parasitology 135, 1225-1235.

Foreyt, W.J., Drew, M.L., Atkinson, M., McCauley, D., 2009, Echinococcus granulosus in Gray Wolves and Ungulates in Idaho and Montana, USA. J. Wildl. Dis. 45, 1208-1212.

Lobachev, Y.S., Bekenov, A.B., 2003, The number of wolves in Kazakhstan. Selevinia, 150-157. (in Russian)

Martin, T.G., Wintle, B.A., Rhodes, J.R., Kuhnert, P.M., Field, S.A., Low-Chow, S.J., Tyre, A.J., Possingham, H.P., 2005, Zero tolerance ecology: improving ecological inference by modelling the source of zero observations. Ecology Letters 8, 1235-1246.

Moks, E., Jogisalu, I., Saarma, U., Talvik, H., Jarvis, T., Valdmann, H., 2006, Helminthologic survey of the wolf (Canis lupus) in Estonia, with an emphasis on Echinococcus granulosus. J. Wildl. Dis. 42, 359-365.

Ruegg, S.R., Heinzmann, D., Barbour, A.D., Torgerson, P.R., 2008, Estimation of the transmission dynamics of Theileria equi and Babesia caballi in horses. Parasitlogy 135, 555-565.

Skryabin, K.I., Petrov, A.M., 1964, Fundamentals of Veterinary micropropagation and nematology. Kolos, 527 pp. (in Russian)

Sobrino, R., Gonzalez, L.M., Vicente, J., de Luco, D.F., Garate, T., Gortazar, C., 2006, Echinococcus granulosus (Cestoda, Taeniidae) in the Iberian wolf. Parasitology Research 99, 753-756.

Torgerson, P.R., Oguljahan, B., Muminov, A.E., Karaeva, R.R., Kuttubaev, O.T., Aminjanov, M., Shaikenov, B., 2006, Present situation of cystic echinococcosis in Central Asia. Parasitology International 55, S207-S212.

Torgerson, P.R., Shaikenov, B.S., Baitursinov, K.K., Abdybekova, A.M., 2002, The emerging epidemic of echinococcosis in Kazakhstan. Transactions of the Royal Society of Tropical Medicine \& Hygiene. 96, 124-128.

Torgerson, P.R., Shaikenov, B.S., Rysmukhambetova, A.T., Abdybekova, A.M., Usenbayev, A.E., Bairtursinov, K.K., 2003a, Modelling the transmission dynamics of Echinococcus granulosus in cattle and sheep in Kazakhstan. Veterinary Parasitology 114, 143-153.

Torgerson, P.R., Shaikenov, B.S., Rysmukhambetova, A.T., Abdybekova, A.M., Usenbayev, A.E., Bairtursinov, K.K., 2003b, Modelling the transmission dynamics of Echinococcus granulosus in dogs in rural Kazakhstan. Parasitology 126, 417-424.

Ziadinov, I., Deplazes, P., Mathis, A., Mutunova, B., Abdykerimov, K., Nurgaziev, R., Torgerson, P.R., 2010, Frequency distribution of Echinococcus multilocularis and other helminths of foxes in Kyrgyzstan. Veterinary Parasitology 171, 286-292.

Ziadinov, I., Mathis, A., Trachsel, D., Rysmukhambetova, A.T., Abdyjaparov, T.A., Deplazes, P., Torgerson, P.R., 2008, Canine echinococcosis in Kyrgyzstan: epidemiology and transmission analysis incorporating diagnostic uncertainty. International Journal for 
Parasitology 38, 1179-1190.

199 